\title{
Why on Earth Is Learners' Patience Wearing Thin: The Interplay between Ambiguity Tolerance and Reading Comprehension Valence of Iranian Intermediate Level Students
}

\author{
Hadi Yaghoubi Nezhad \\ Department of Foreign Languages, Kharazmi University, Tehran, Iran \\ Isa Atarodi \\ Department of Foreign Languages, Kharazmi University, Tehran, Iran \\ Maryam Khalili \\ Department of Foreign Languages, Kharazmi University, Tehran, Iran
}

\begin{abstract}
Research supports the effectiveness of using preferred learning styles in the process of language acquisition. It has been shown that successful language learners often tap into relevant styles and strategies effectively in the process of learning a foreign language. Following fads and fashions in this line of research, this paper tries to examine the relationship between ambiguity tolerance and learner's reading comprehension ability. For this purpose 22 Iranian fresh university students were chosen. At first they filled a questionnaire with regard to Ambiguity Tolerance scale. During next sessions their reading comprehension ability was examined. Correlational procedure was used for the purpose of this study. It was generally shown that there is a positive correlation $(\mathbf{0 . 8 3})$ between ambiguity tolerance and reading comprehension ability.
\end{abstract}

Index Terms-Ambiguity tolerance, reading comprehension

\section{INTRODUCTION}

Language learning is an extremely exacting endeavor. Learners are stampeded with novel and new information that must be processed, assimilated and anchored to existing knowledge. Unfortunately, this is no easy task. The structural, lexical, and phonological elements of any two languages do not enjoy one-to-one correspondence. Whether learning takes place in educational or environmental settings, whether language learning is communicatively oriented or not, the learner has to cope with uncertainties originating partly from this dearth of complete correspondence between any two languages.

The case seems even worse when a quick comparison is made between English and Persian. Test results and research findings have shown that Iranian students are weak at their reading comprehension ability of English texts (Fahim and Sa'eepour, 2011). This fact is evident from their continuous complaints after university entrance examination. It consists of a couple of English texts most of which are skipped by students. Needless to say, there are many differences between writing styles, format and organization of English and Persian texts that result in students' unfamiliarity and consequent sense of ambiguity. Different groups of learners react differently to English texts. Some may take it easy and go ahead with the task of reading a different text type till they comprehend it and some others may be less flexible and get confused with this task. Reactions of this latter group of students may result in ambiguity and intolerance of the difference and so their lagging behind the first sentences and losing the required time to go through the whole passage. A quality that assists learners to overcome these kinds of uncertainties intrinsic in language learning is tolerance of ambiguity (Kazamia, 1998).

This study can have bidirectional significance. Specifically, it may generate results that can be settled in domestic environment in order to help weak readers to develop more tolerance of ambiguity while reading English texts. Generally speaking, it can contribute to the total field of psycholinguistics, with producing results generalizable to individuals with similar style preferences. Up to now fewer researches have been done in Iran to see if these facts are also true of Iranian students. With respect to the fact that today learning English has received considerable spotlight in Iran, and many institutes try to enhance the students' level of proficiency, therefore any factor which seems to affect learning of English warrant investigation. The present study is carried out to address this question:

Does ambiguity tolerance have any effect on reading comprehension ability of Iranian intermediate level learners?

\section{REVIEW OF LITERATURE}


According to Brown (1994) ambiguity tolerance "concerns the degree to which people are cognitively willing to tolerate ideas and propositions that run counter to their own belief system or structure of knowledge. Some people are, for example, relatively "open-minded" in accepting ideologies, events and facts that contradict their own views; they are more content than others to entertain and even internalize contradictory propositions. Others, more "close-minded", more dogmatic, tend to reject items that are contradictory or slightly incongruent with their existing system; they wish to see every proposition fit into an acceptable place in their cognitive organization, and if it does not fit, it is rejected." Before addressing empirical researches done in this respect it is worth mentioning the pioneering efforts perpetrated to design some measuring scale on this learning style preference.

\section{A. Scales for Measuring Tolerance of Ambiguity}

The first problem in trying to assess the influence of tolerance/intolerance of ambiguity, of course, is to develop a means of measuring the construct. Perhaps the most widely used measure of ambiguity tolerance is the 16-item scale devised by Budner (1962), but nonetheless the internal consistency of this scale is realized to be extremely low (0.49). Furnham (1994) suggested that this may be ascribable partly to an underlying multidimensional structure, and based on a factor analysis he suggested a four-factor solution. But nonetheless, the scale correlated weakly with other tolerance of ambiguity instruments, and a recent confirmatory factor analysis of Budner's scale by Benjamin, et al (1996) failed to confirm either the single factor structure hypothesized by Budner (1962) or the four factor model proposed by Furnham (1994). Another widely used scale for measuring ambiguity tolerance is the McLain's new measure (1993) of an individual's tolerance for ambiguity. This scale has the reliability of .87. It includes 22 items and is used by McLain to measure ambiguity tolerance in general. Other measures of ambiguity tolerance have included the 16-item scale devised by Rydell and Rosen (1966), but this was not factor-validated and no internal reliability data were reported. Subsequently Macdonald (1970) found that the scale had poor internal reliability, but this was increased to 0.62 when four new items were added. Kirton (1981) later viewed Budner/ Reydell and Rosen/Macdonald scales, combining them into a single 18-item instrument with improved but nonetheless only modest internal reliability $(0.71)$.

All the above-mentioned instruments have tried to measure the construct of ambiguity tolerance in general, and neither is specifically concerned with language learning settings. Until fairly recently, most psychologists have maintained that one's characteristics are fairly consistent from one situation to another (Ely, 1989). However, in the last several decades a small but influential group of personality researchers (Mischel, 1968, Endler, 1973) have found that it is not always feasible to use "global" (general) personality instruments to predict how an individual will behave in a certain circumstance.

The need to put into operation personality variables in the specific context of second language learning first was addressed by Chapelle (1983), but she considered the scale to be "somewhat suspect as a consistent measure of ambiguity tolerance", since the original 13-item scale had to be reduced to 4 items in order to obtain a reliability of 0.54 (Cronbach alpha).This scale was not apparently used in Chappelle's subsequent analyses (Ely, 1989).Then Ely (1989) developed an ambiguity tolerance scale designed for the purpose of measuring individual differences in the specific environment. This version of the situation-specific ambiguity tolerance scale consist of 12 items, representing various aspects of language learning and use, including pronunciation, speaking, listening, reading comprehension, lexical development and grammar learning.

\section{B. A Brief Review of Empirical Research on Ambiguity Tolerance}

A few research findings are available on ambiguity tolerance in second language learning. In their comprehensive study of the predictors of language achievement, Naiman et al. (1978) used Budner's global scale of ambiguity tolerance with English-speaking high school students of French. Eighth-grade students who were tolerant of ambiguity performed better on both receptive and productive language tests. Some researchers investigated the predictability of this style in language achievement and proficiency. Chapelle (1983), for example, using Norton's scale found that global ambiguity tolerance was a predictor of final TOEFL scores of ESL university students. Reiss (1985) found a positive relationship between ambiguity tolerance and university foreign language students' rating of themselves as language learners. Albeit Reiss measured ambiguity tolerance with three situation specific items, she apparently did not make an attempt to develop a psychometrically reliable tolerance of ambiguity instrument.

In another study Chappele and Roberts (1986) studied the role of ambiguity tolerance in performing language tasks. They measured ambiguity tolerance in learning of English as a second language in Illinois. What they found was that learning with a high tolerance and endurance for ambiguity was slightly more successful in certain language tasks. Having tried to assess the degree of ambiguity tolerance of Greek civil servants in learning English as a foreign language, Kazamia (1998) found that Greek adult learners did not show the same tolerance in all skills and in all language learning strategies. First, in one set of items the scores showed a high degree of intolerance among learners. The common denominator in these items was that they all referred to conveyance of ideas on the part of learners. It is obvious that Greek civil servants cannot endure the fact that they are not able to express their ideas with clarity and exactness when speaking or writing English. In another set of items, moderate level of ambiguity tolerance could be seen when reading English. It showed that participants of this study were willing to tolerate the uncertainty entailed in guessing. Also it was shown that some individuals were able to tolerate the fact that they were not able to understand some lexical items pronounced by their instructors. However they may not be that tolerant when they fail to understand 
the majority of teacher's talk. Also it was found that although learners tolerate moderate ambiguities arising from grammatical elements, their tolerance decreases when failing to apply grammar in speaking and writing.

Hakk Erten and Zehir Topkaya (2009) tried to investigate the nature of ambiguity tolerance in reading in a foreign language among Turkish learners of English and to determine likely relationships between ambiguity tolerance and different personal and cognitive variables such as gender, proficiency level, perceived success in reading and strategy training. Their statistical analysis revealed students' lower tolerance for ambiguity in the process of learning, hence this conclusion that learners in an EFL context are generally less tolerant of ambiguity. Another aspect of ambiguity that had been explored in their study was gender differences. Females were found to be less tolerant of ambiguities in the language classroom than their male peers. Their findings also suggested a significant difference between ambiguity tolerance and learners' language proficiency levels, indicating that the higher the proficiency level, the more tolerant learners become in foreign language learning. The last aspect of their study dealt with ambiguity tolerance, success in reading and strategy training. They reported a significant correlation between these variables. As such, the more students were trained about strategies they could tap into while reading in a foreign language, the more tolerant they can become of ambiguities and uncertainties, which may ultimately bring success in reading in a foreign language.

Locally observed, a couple of studies have been recently done in Iran to examine the relationship and interplay between ambiguity tolerance and other constructs; reading strategy use, gender, and performance on close test, to name just a few.

Keshavarz and Assar (2009) investigated the differences among Iranian high, mid and low ambiguity tolerance groups in their reading comprehension ability and their metacognitive awareness of reading strategies. Their results revealed significant differences between low and high groups, i. e. high ambiguity tolerance students scored higher on reading comprehension test, showed higher metacognitive awareness of reading strategies, and displayed higher perceived use of global and problem-solving metacognitive reading strategies. However, they found no significant differences between the middle group and the other two groups in these variables. Also, they reported no significant difference in the use of supportive strategies among these three groups. Ashouri and Fotovatnia (2010) examined learners' beliefs about translation and the impact of two variables of individual differences, namely, risk taking and tolerance of ambiguity, on the mentioned variable. Their study revealed that EFL learners had a positive belief in EFL learning. It reported that risk-taking affected learners' translation belief significantly in the way that risk-averse learners had a positive belief which is in contrast with risk-takers who had negative belief about translation. Their analysis of the data on the effect of ambiguity tolerance on translation belief revealed that this individual characteristic had no effect on learner's translation belief. As a result, although they found risk-taking to be significantly effective on translation belief, no such an effect was reported of ambiguity tolerance. Karbalaee (2011) tried to examine both the patterns of ambiguity tolerance among Iranian English language learners and the existence of any statistically significant difference between Iranian male and female learners' in their ambiguity tolerance. Her results revealed that participants' average ambiguity tolerance score were highest in items related to reading skill and the lowest in items pertained to writing skill. With respect to gender effect, no statistically significant difference was revealed between Iranian male and female English language learners in their ambiguity tolerance. Atef-Vahid, et al (2011) explored levels of ambiguity tolerance among Iranian high school students in EFL classrooms and its relationship with cloze test performance. The instruments used in this study were Second Language Tolerance of Ambiguity Scale (SLTAS) (Ely 1995) and a standardized English cloze test. Their results displayed that respondents with higher levels of ambiguity tolerance were likely to obtain higher scores on the cloze test, and those with lower levels of ambiguity tolerance tended to gain lower scores on the cloze test. Maftoon and Karbalaee (2012) attempted to examine whether any statistically significant relationship existed between Iranian EFL learners' AT (ambiguity tolerance) and their reading strategy use. Using an ambiguity tolerance scale similar to that of present study they found no statistically significant relationship between participants' AT and their overall reading strategy use. Further, their results displayed a statistically significant and positive relationship between AT and reading comprehension scores of the participants, which as will be shown later supports the finding of present study.

\section{METHOD}

\section{A. Participants}

A total number of 22 female students were chosen. All of them were students of Kharazmi University with different majors, their age ranging from 18 to 23. They enrolled at a pre-TOEFL class. Their level of English proficiency was reported to be intermediate, so they seemed appropriate for the purpose of study.

\section{B. Instrumentation}

\section{Ambiguity tolerance questionnaire}

The questionnaire used for this purpose belongs to McLain (1993). It should be mentioned that from among the items included in the questionnaire, questions number $1,2,3,4,5,6,11,13,14,15,16,18$, and 22 were exactly what Ely (1995) had used in his situation-specific study of ambiguity tolerance scale. The rest of questions were based on McLain's scale and on a general understanding of what makes a situation ambiguous and also on teaching experience.

2. Reading passages 
Having surfed the relevant websites (including TOEFL), the researchers found appropriate reading passages tailored to subject's level of English proficiency. With reference to the difficulty level of passages, they had been measured up to the intermediate level of students.

\section{Design}

According to Farhadi (1995) there are three major research designs: descriptive, correlational, and experimental. The present study is correlational because it aims at finding meaningful relationship among the variables under study. As a result, the design of the study is ex post facto. In this design the researcher does not have any control over the selection and manipulation of independent variables. Also the researcher has no control over what has happened to the students and any relationship between the scores of the groups would not be related to any instructional program they might have encountered.

\section{Procedure}

Having translated the McLain's scale of Ambiguity tolerance into Persian, the researchers had some English professors ensure its content validity. The scale consisted of 22 items, each one containing six choices ranging from completely agree to completely disagree (Likert Scale). These choices were assumed to have values from 6 to 1 . So the total score of the exam was 132.In the second phase, a session was arranged with the instructor of the pre-TOEFL class and the questionnaires were distributed among the subjects. They answered it in 15 minutes. With the span of three weeks, during the third step, subjects were provided with the reading passages. As was mentioned before, it contained four reading passages, each one followed by 5 reading comprehension items with total score of twenty. The allocated time was 45 minutes. In the final phase, i.e. after administering the test, the papers were scored and put into the SPSS software for analysis. Then their scores on both exams were correlated which are presented in the following section, accompanied by some interpretation.

\section{RESULTS AND DisCUSSION}

As it is presented in the statistical descriptions, Pearson correlation was used in this study to analyze the obtained data. The reason behind this choice was discovering any relationship between the two groups of scores: the scores of reading comprehension test and the degree of ambiguity tolerance. Following tables show a positive relationship between ambiguity tolerance and reading comprehension ability (.0<.05). Based on the correlation index obtained (0.83) it can be inferred that there is a high correlation between ambiguity tolerance and reading comprehension ability, that is to say, the more ambiguity tolerant the students are, the higher their reading comprehension scores will be.

TABLE I

DESCRIPTIVE STATISTICS OF AMBIGUITY TOLERANCE AND READING COMPREHENSION

\begin{tabular}{|c|c|c|c|c|c|}
\hline \multicolumn{6}{|c|}{ Paired Samples Statistics } \\
\hline & & Mean & $\mathrm{N}$ & Std. Deviation & $\begin{array}{c}\text { Std. Error } \\
\text { Mean }\end{array}$ \\
\hline Pair & Ambug-Toler & 90.3182 & 22 & 14.46304 & 3.08353 \\
\hline 1 & Read-Compre & 15.5000 & 22 & 1.87083 & .39886 \\
\hline
\end{tabular}

TABLE II

CORRELATION BETWEEN AMBIGUITY TOLERANCE AND READING COMPREHENSION

Paired Samples Correlations

\begin{tabular}{|ll|r|r|r|}
\hline & & $\mathrm{N}$ & Correlation & \multicolumn{1}{c|}{ Sig. } \\
\hline $\begin{array}{l}\text { Pair } \\
1\end{array}$ & $\begin{array}{l}\text { Ambug-Toler \& } \\
\text { Read-Compre }\end{array}$ & 22 & .835 & .000 \\
\hline
\end{tabular}

Findings of this piece of research are in line with the previously mentioned works, particularly those of Kazamia, Keshavarz and Assar, and Maftoon and Karbalaee. As was stated before, these researchers generally found statistically significant and positive relationship between ambiguity tolerance and reading comprehension scores of the participants, which supports the finding of present study. On the other hand, some contradictory and curious evidence to Hakk Erten and Zehir Topkaya's findings was traced in this study. They came across with Turkish students' lower tolerance for ambiguity in the process of learning a foreign language, and consequently concluded that learners in an EFL context are generally less tolerant of ambiguity. However informative and insightful their study may be, it is not substantiated by the finding of present study. The high index of 0.83 suggests a significant positive correlation between ambiguity tolerance and reading comprehension ability, indicating the fact that ambiguity tolerance does make contribution to the process of learning a foreign language.

\section{CONCLUSION}


Following the research trends in the area of learning styles and strategies this paper made an attempt to investigate the relationship between ambiguity tolerance and learner's reading comprehension ability. Correlational procedure showed that there is a positive and hence significant correlation between these two variables. Findings of this study supports the idea that learners' preferred learning styles, ambiguity tolerance in this case, play a major role in their reading comprehension. As Ely (1989) believed perhaps the central implication of this study concerns the way in which teachers view and present language learning styles and strategies. Although some teachers are now becoming aware of the importance of individual learning style and personality characteristics in language learning, often little has been done in practice. Therefore it is incumbent upon teachers to raise students' awareness of their preferred learning style and provide them with proper opportunities to draw on these styles. One way to do this, of course, is by supplying different reading passages and asking students to be more tolerant of ambiguity and uncertainties and not dismissing the whole passage once encountered with the first unfamiliar vocabularies. After enriching their class with more learnerfriendly and style-oriented tasks they can move more quickly toward helping their students to become successful language learners. The last but not least point is that the major focus of current study was on tolerance of ambiguity. It is certain that there are many other individual characteristics at students' disposal that warrant investigation. Classroom teachers are in the best position to observe these variables and decide which one to implement in future research projects.

\section{REFERENCES}

[1] Ashouri , A.F., \& Fotovatnia, Z. (2010). The Effect of Individual Differences on Learners' Translation Belief in EFL Learning. English Language Teaching, 3(4), 228-236.

[2] Atef-Vahid, S., Fard Kashani, A., \& Haddadi, M. (2011). The relationship between levels of ambiguity tolerance and cloze test performance of Iranian learners. Linguistic and Literary Broad Research and Innovation, 2(2), 149-169.

[3] Benjamin, A.J., Riggio, R.E., \& Mayes, B.T. (1996). Reliability and factor structure of Budner's Tolerance for Ambiguity Scale. Journal of Social Behavior and Personality, 3(11), 625-632.

[4] Budner, S. (1962). Intolerance of ambiguity as a personality variable. Journal of personality, 3(1), 29-50.

[5] Brown, H. D. (1994). Principles of language teaching and learning. London. Prentice hall.

[6] Chappelle, C. (1983). The relationship between ambiguity tolerance and success in acquiring English as second language learning in adult learners. Dissertation, university of Illinois.

[7] Chapelle, C. \& Roberts, C. (1986). Ambiguity tolerance and field independence as predictors in English as a second language. Language Learning, 36(1), 27-45.

[8] Ely, C. (1989). Tolerance of ambiguity and use of second language learning strategies. Modern Language Journal 22(5), 437445.

[9] Ely, C.M (1995). Tolerance of ambiguity and the teaching of ESL. In J. Reid (Ed.), Learning styles in the ESL/EFL classroom, 87-95. Boston: Heinle and Heinle.

[10] Endler, N. S. (1973). The person versus the situation: A pseudo issue? A response to Alker. Journal of Personality, 41(2), 287303.

[11] Fahim, M., \& Sa'eepour, M. (2011). The Impact of Teaching Critical Thinking Skills on Reading Comprehension of Iranian EFL Learners. Journal of Language Teaching and Research, 2(4), 867-874.

[12] Farhadi, H. (1995). Research method in applied linguistics. Tehran: Payam-Nour University Press.

[13] Furnham, A. (1994). A content, correlational and factor analytic study of 4 tolerances for ambiguity questionnaire. Personality and Individual Differences. 16 (3), 403-410.

[14] Hakk Erten, I. \& Zehir Topokaya, E. (2009). Understanding Tolerance of Ambiguity of EFL Learners in Reading Classes at Tertiary Level. Novitas-ROYAL, 3(1), 29-44.

[15] Karbalaee Kamran, S. (2011). Effect of Gender on Ambiguity Tolerance of Iranian English language learners. Journal of Education and Practice, 2(11\&12), 25.

[16] Kazamia, V. (1998). How tolerant are Greek learners of foreign language ambiguity. Department of linguistics and phonetics. University of leads.

[17] Keshavarz, M.H. \& Assar, M. (2009). Reading Comprehension Ability and Metacognitive Awareness of Reading Strategies among High, Mid and Low Ambiguity Tolerance EAP Students. Iranian Journal of Applied Linguistic Studies. 1(2), 71-108.

[18] Kirton, M.J. (1981). A reanalysis of 2 scales of tolerance of ambiguity. Journal of Personality Assessment. 45 (4), $407-414$.

[19] Macdonald, A.P. (1970). Revised scale for ambiguity tolerance. Psychological Reports.26 (3), 791-798.

[20] Maftoon , P., \& Karbalaee Kamran, S. (2012). An Analysis of the Associations between Ambiguity Tolerance and EFL Reading Strategy Awareness. English Language Teaching, 5(3), 188-196.

[21] McLain, D.L. (1993). MSTAT-1: a new measure of an individual tolerance for ambiguity. Educational and Psychological Measurement. 53 (1), 183,189.

[22] Mischel, W. (1968). Personality and assessment. New York: Viley.

[23] Naiman, N., Frohlich, M., Stern, H., \& Todesco, A. (1987). The good language learner. Toronto: Ontario institute for studies in education.

[24] Norton, R.W. (1975). Measurement of ambiguity tolerance. Journal of Personality Assessment.39 (6), 607-619.

[25] Reiss, M. (1985). "The good language learner: Another look”, Canadian Modern Language Review, 41(3), 257-266.

[26] Rydell, S. T. \& E. Rosen. (1966). "Measurement and some correlates of need-cognition." Psychological Reports, 19(1), 13031312. 
Hadi Yaghoubi Nezhad holds an MA in TEFL from Kharazmi University of Tehran. His research interest includes Bilingualism, CALL, Consequential Validity Research, and Learning Styles and Strategies. He has been teaching English for more than 10 years. $\mathrm{He}$ is currently a visiting professor at Kharazmi University.

Isa Atarodi holds an MA in TEFL from Kharazmi University of Tehran. His research interest includes CALL, Language Skills and Subskills, Phraseology in language, in particular Collocations. He has been teaching English for 11 years. He is currently a visiting professor at Qom University and Mofid University.

Maryam Khalili is an MA holder in TEFL from Kharazmi University of Tehran. Her main areas of interest are CALL, Discourse Analysis, Sociolinguistics, and Teaching Methodology. 